\title{
Comment
}

\section{Considerações sobre o Instituto do Lawfare}

\author{
Geraldo Carreiro de Barros Filho ${ }^{1}$; Athena de AlbuquerqueFarias ${ }^{2}$; Gislene Farias de Oliveira ${ }^{3}$
}

Resumo: Lawfare é um termo que não tem definição fixa. É entendido de forma geral como sendo o uso indevido da lei, como meio para alcançar objetivos militares. Estaria preocupado com a isntrumentalização da lei para alcançar fins estratégicos políticos. A idéia é eliminar, deslegitimar ou incapacitar os oponentes. Suas características são discutíveis, dado o incitamento ao ódio, pela condenação prévia do que ainda não foi julgado.

Palavras- Chave: Lawfare. Lei. Direito.

\section{Lawfare Institute Considerations}

\begin{abstract}
Lawfare is a term that has no fixed definition. It is generally understood as the misuse of the law as a means to achieve military objectives. It would be concerned with the implementation of the law to achieve political strategic goals. The idea is to eliminate, delegitimize or disable opponents. Its characteristics are debatable, given the incitement to hatred, by the previous condemnation of what has not yet been judged.
\end{abstract}

Keywords: Lawfare. Law. Law Course.

\section{Conceituando o Instituto do Lawfare}

O termo Lawfare foi popularizado nos Estados Unidos pelo Major General da Força Aérea Americana, Charles Dunlap em 2001, engendrando desde então uma difusão indeterminada do seu significado. O termo "lawfare" não tem definição fixa, mas passou a ser entendido de forma geral como: "O uso indevido da lei como substituto dos meios militares tradicionais para alcançar objetivos militares”.

\footnotetext{
1 Mestrando em Educação pela Anne Sullivan University, Florida/EUA. Especialista em Direito Constitucional pela Universidade Estácio de Sá, Rio de Janeiro/RJ. Bacharel em Comunicação Social. Relações Públicas pela Escola Superior de Relações Públicas, Recife/PE. Acadêmico de Direito: Faculdade Paraíso do Ceará, Juazeiro do Norte/CE. http://lattes.cnpq.br/4226086257152901. E-mail: carreirog@ hotmail.com;

${ }^{2}$ Advogada pela Faculdade dos Guararapes. Especialista em Direito Processual do Trabalho pela Faculdades Integradas de Cruzeiro - SP. Editora Adjunta do Periódico Científico Id on Line Revista Mutidisciplinar e de Psicologia. http://lattes.cnpq.br/6523516622985659. E-mail: athena.farias@gmail.com;

${ }^{3}$ Doutora em Psicologia Social pela Universidade Federal da paraíba. Pós Doutorado em Ciências da saúde pela Faculdade de Medicina do ABC - São Paulo, Brasil. http://lattes.cnpq.br/5084510934957372. Orientadora.
} 
Id on Line Revista Multidisciplinar e de Psicologia

Id on Line Multidisciplinary and Psycology Journal

Lawfare está preocupado com a isntrumentalização ou politicalização da lei para alcançar um efeito tático, operacional ou estratégico. No âmbito propriamente político e das leis, é uma expressão que faz referência ao fenômeno do uso abusivo e superficial do direito, nacional ou internacional, como forma de se atingirem objetivos militares, econômicos e políticos, eliminando, deslegitimando ou incapacitando um inimigo. Lawfare pode ser concebido como o termo que define o uso do Direito para deslegitimar ou incapacitar um inimigo. Tendo então suas características ou táticas já reconhecidas pela comunidade jurídica internacional, quais sejam: a) A manipulação do sistema legal. b) Dar aparência de legalidade para perseguições políticas. c) A utilização de processos judiciais sem qualquer mérito, sem conteúdo, com acusações frívolas. d) Abuso do direito para danificar e para deslegitimar um adversário. e) Promoção de ação judicial para descredibilizar o oponente. f) Tentativa de influenciar a opinião pública. g) Utilização da lei para obter publicidade negativa ou opressiva. h) Judicialização da política: a lei como instrumento para conectar meios e fins políticos. i) A promoção da desilusão popular. j) A crítica àqueles que usam o direito internacional e os processos judiciais para fazer reinvindicações contra o Estado. k) A utilização do direito como forma de constranger e punir o adversário. 1) Acusação das ações dos inimigos como imorais e ilegais, com o fim de frustrar objetivos contrários.

A palavra Lawfare é a junção das palavras americanas law, que significa lei, e warfare, que significa conflito armado, guerra. Lawfare então faz referência ao uso da lei como arma de guerra.

Assim, convidando ao exercício hermenêutico, diz ser o abuso das leis e dos sistemas próprios do Ordenamento jurídico com intuitos bélicos ou políticos. Quais sejam tais esforços de entendimentos exemplificados nos processos legais com violações intimidadoras, frustrantes dos empenhos dos oponentes; trazendo à seara jurídica um novo adjetivo: campo de batalha legal.

O site lawfareproject.org se refere aos fins políticos do Lawfare de forma aversiva:

Lawfare significa o uso da lei como uma arma de guerra. Denota o abuso das leis ocidentais e sistemas judiciais para conseguir fins militares estratégicos ou políticos. Lawfare é inerentemente negativa. Não é uma coisa boa. É o oposto da busca de justiça. É a apresentação de processos judiciais frívolos e mau uso 
de processos legais para intimidar e frustrar adversários no teatro de guerra.

Lawfare é o novo campo de batalha legal (THE LAWFARE PROJECT, 2016).

Ainda no sentido de arma de guerra, Susan Tiefenbrun (2010) ${ }^{1}$ define o fenômeno como sendo: "uma arma projetada para destruir o inimigo através do uso, mau uso e abuso do sistema legal e dos meios de comunicação, para levantar o clamor público contra aquele inimigo". Como ressalta Dunlap Jr. (2001), preceptor do termo, são violações legais reais, percebidas ou até mesmo orquestradas e empregadas como um meio de confronto não usual.

\section{O fenômeno no Brasil}

Lawfare é um instituto que se origina no direito internacional e ora vem sendo utilizado, como tese de defesa brasileira, mas por que trazer à baila tal instituto e lançar mão dessa estratégia de defesa em processo criminal, se não há estado de guerra declarada entre pessoa física e o Estado representante do povo?

Há questões carentes de exercício de ponderação e que de forma didática, o presente artigo tenta trazer entendimentos de diversos autores.

No caso do fenômeno no Brasil, o uso do lawfare é um meio para fins políticos e econômicos, não estando restringido apenas ao contexto de conflitos armados.

John Gledhill (2016), ao estudar a conjuntura brasileira, compôs: "o que estamos vendo no Brasil é a forma como a aplicação seletiva do que poderia ser descrito como "lawfare" está promovendo um clima de desilusão popular em que um governo democraticamente eleito pode ser removido do poder."

De fato, conforme orienta Orde Kittrie (2016), especialista em Lawfare , “[...] a lei está se tornando, gradativamente, uma poderosa e prevalente arma de guerra".

O uso da lei como uma ferramenta estratégica tem sido reconhecida como significante para obtenção de vantagens políticas ou militar, com ênfase em enfraquecer, gerando reações negativas. Objetiva-se minar a resolução de forças militares, e gerar reações negativas por parte da população com o poder político. Esse tipo de Lawfare implica em reações que instrumentalizam a Injustiça através de restrições legais, que se aplicam a um dos lados, em detrimento a uma indiferença desenfreada no cumprimento legal pelo outro lado. 
Id on Line Revista Multidisciplinar e de Psicoloqia

Id on Line Multidisciplinary and Psycology Journal

A operação "Lava Jato", assim denominada pelo Ministério Público Federal (MPF), é a maior investigação de corrupção e lavagem de dinheiro que o Brasil já teve. Ela representa um típico exemplo de lawfare, assim sendo, trata-se da utilização de meios judiciais frívolos, com aparência de legalidade para cooptação da opinião pública, com o inegável objetivo de neutralizar o inimigo eleito. A prática do lawfare é um dos argumentos usados pela defesa de agentes políticos conhecidos dentro da investigação, pois os próprios agentes públicos participantes das investigações promovem uma guerra contra o 'inimigo eleito' e contra o projeto político que ele representa e que os apontamentos do MPF são tidos como "imputações frívolas" sob aparência de legalidade, o que acaba por encobrir as irrefutáveis perseguições e as ilegalidades perpetradas.

Listam-se também uma série de táticas usadas pela operação para deslegitimar o inimigo eleito, entre elas a manipulação do sistema legal, o abuso de direito, tentativa de influenciar a opinião pública, judicialização da política e promoção de desilusão popular, essas características marcantes do instituto do lawfare.

Sobre Judicialização da política aqui entendida como o interesse de políticos e autoridades administrativas em adotar condutas semelhantes aos processos judiciais. A judicialização da política ocorre quando os tribunais são chamados a se pronunciar diante de questões sociais de cunho político, onde o funcionamento do Legislativo e do Executivo se mostram falhos, insuficientes ou insatisfatórios. Sob tais condições, ocorre uma certa aproximação entre Direito e Política e, em vários casos, torna-se mais difícil distinguir entre um "direito" e um "interesse político" (CASTRO, 1994), sendo possível se caracterizar o desenvolvimento de uma "política de direitos" (TATE, 1995).

\section{O discurso contra o "inimigo eleito"}

Ao que consta dos processos em curso - envolvendo políticos do alto escalão nacional, vemos que há por ocasiões uma tentativa de exposição dos desmandos e desacertos ocasionados pelo 'inimigo eleito', quando este se encontrava em pleno exercício do poder. Tal procedimento denota um pré-julgamento e consequentemente condenação por parte dos que não dominam as 
ciências jurídicas e tão somente se favorecem com a exposição de estigmas desestabilizadoras dos poderes.

O "discurso de ódio" não parece serir como argumento e, nesse sentido jurisprudencial, temos referência no texto pertinente do Ministro do Supremo Tribunal Federal, Luiz Fux:

Pelo Pacto dos Direitos Civis e Políticos, que foi internalizado em nosso país pelo Decreto n' 592 de 1992, estipula em seu art. 20 que 'Será proibida por lei qualquer apologia do ódio nacional, racial ou religioso que constitua incitamento à discriminação, à hostilidade ou a violência. (STF, 2013).

Ainda, quando um Tribunal Internacional demonstra viés político ou outro em suas deliberações, o controle soberano do Estado é $a b$-rogado?

É cediço que os tratados recepcionados no Ordenamento Jurídico Brasileiro, tem força de emenda constitucional e por este diapasão as Cortes Internacionais, independentes na condução dos processos sobre seus ombros, deve acautelar-se quanto forças políticas travam batalhas, com vistas a influenciar nas suas decisões, respingando no que a legislação nacional não tolera, não endossa.

Convida-se então a esclarecer o que vem a ser $a b$-rogar:

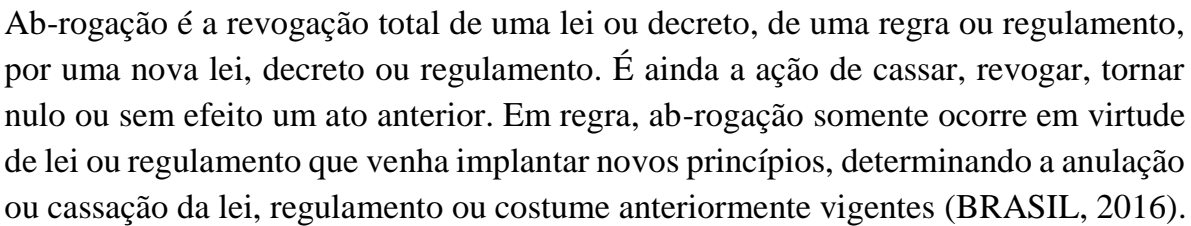

Por este diapasão temos que o ódio - agente contaminador, corrompe o processo, aliena os sujeitos processuais e traz possibilidade de nulidade, ab-rogando qualquer decisão tomada com o mínimo de imparcialidade.

Assim, a bem da segurança jurídica acredita-se que não há que pensar em ab-rogação de qualquer das alíneas constantes em nosso Ordenamento jurídico em relação ao Estado, pelos motivos elencados. 
Id on Line Revista Multidisciplinar e de Psicoloqia

Id on Line Multidisciplinary and Psycology Journal

\section{Considerações Finais}

É o objetivo deste artigo, rever tal fenômeno para destacar como o direito está situado dentro de um terreno político mais amplo, também moral e social nas tomadas de decisões. Há ações contra lawfare por este, supostamente, divulgar uma série de pressupostos.

O que o fenômeno do lawfare faz, é destacar as percepções das limitações sob o quadro positivista, em abordar e contrariar objetivos. Todos os relatos contemporâneos do positivismo revelam hoje, um nível de espaço interpretativo, onde considerações sociais e políticas mais amplas podem ser infundidas na interpretação jurídica.

O incitamento ao ódio e erro do 'inimigo eleito' traz imediata condenação daquele que ainda não foi julgado e condenado, seja ele conhecido ou desconhecido da população população essa que muitas vezes traz em seu bojo a "guilhotina" e a condenação para além do que a lei diz ser suficiente ao crime cometido, após a sentença prolatada.

\section{Referencias}

BRASIL. STF. ARE $678112 R G$, Relator: Min. LUIZ FUX, julgado em 25/04/2013, Acórdão eletrônico. Repercussão Geral - Mérito. DJe 17-05-2013

CASTRO, M.F. de.(1994), "Dívida externa, globalização da economia e direitos humanos". Arquivos do Ministério da justiça, 184, ano 47, jul./dez. 1994: 125-44.

DALE, Stephens. The age of lawfare. International law studies, vol 87, 2011

DUNLAP JR., Charles J. Law and Military Interventions: Preserving Humanitarian Values in 21 st Conflicts presented at Humanitarian Challenges in Military Interventions Conference. November, 2001.

GLEDHILL, John. Tradução livre. Do original: "what we are seeing in Brazil is how the selective application of what might be described as 'lawfare' is promoting a climate of popular disillusion in which a democratically elected government can be removed from power". 
Disponível em: <https://johngledhill.wordpress.com/2016/03/17/the-brazilian-political-cr... Acesso em: out. 2016.

KITTRIE, Orde F. Lawfare: Law as a Weapon of War. Oxford: Oxford University Press, 2016.

TATE, C. N.; e VALLINDER, T. (ores.). (1995), The global expansion of judicial power New York, New York University Press.

TIEFENBRUN, Susan. Semiotic Denifition of Lawfare. Tradução livre. Do original: "Lawfare is a weapon designed to destroy the enemy by using, misusing, and abusing the legal system ant the media in order raise public outcry against the enemy". 43 CASE WESTERN J. INT'L LAW 29, 2010.

THE LAWFARE PROJECT. What Is Lawfare? Disponível em: <http://thelawfareproject.org/lawfare/what-is-lawfare-1/> Acesso em: 12.10.2016.

\section{Como citar este artigo (Formato ABNT):}

BARROS FILHO, G.C.; FARIAS, A.A.; OLIVEIRA, G.F. Considerações sobre o Instituto do Lawfare. Id on Line Revista Multidisciplinar e de Psicologia, Janeiro de 2017, vol.10, n.33, Supl 2. p. 363-369. ISSN: 1981 1179 .

Recebido: 05.01.2017

Aceito: 09.01.2017 